\title{
EVALUASI TAMAN PEMULIHAN GIZI TERHADAP PERILAKU IBU BALITA GIZI BURUK DAN GIZI KURANG DI PUSKESMAS JATIWATES KABUPATEN JOMBANG
}

\author{
Evaluation Of Nutrition Restoration Park Towards Bad Nutrition And Less Nutrition Moters \\ At Jatiwates Public Health Jombang District
}

\author{
Septi Fitrah Ningtyas ${ }^{1}$, Niken Grah Prihartanti ${ }^{2}$, Mudhawaroh $^{3}$, Mamik Ratnawati ${ }^{4}$ \\ 1. STIKES Pemkb Jombang
}

\section{Riwayat artikel}

Diajukan: September 2020

Diterima: Maret 2021.

\section{PenulisKorespondensi: \\ - Septi Fitrah Ningtyas \\ - STIKES Pemkab Jombang \\ - septifitrah1@gmail.co $\underline{\mathrm{m}}$}

\section{Kata Kunci:}

Taman Pemulihan Gizi, Perilaku Ibu, Gizi Buruk, Gizi Kurang
Masalah gizi buruk merupakan salah satu masalah yang sering menjadi kontroversi di wilayah Negara Indonesia ini. Menurut Riset Kesehatan Dasar (Riskesdas) 2013, jumlah bayi dibawah usia lima tahun yang mengalami masalah dengan kebutuhan gizi meningkat dari angka 17,9\% tahun 2010 menjadi 19,6\%. Masalah lain yang berkaitan dengan kebutuhan gizi pada balita adalah adanya stunting di Indonesia. Indonesia menjadi urutan nomer lima di dunia akibat angka pravalensi yang cukup tinggi pada stunting. Tujuan dari penelitian ini adalah Menganalisis program Taman Pemulihan Gizi terhadap status gizi balita di wilayah kerja Kecamatan Tembelang.

Penelitian ini menggunakan metode observasional analitik dengan rancangan penelitian kohort retrospektif. Populasi dalam penelitian ini adalah seluruh ibu balita yang memiliki balita gizi buruk di Desa Gabus Banaran \& Desa Pulo Gedang sejumnlah 36 Responden. Teknik sampling yang digunakan dalam penelitian ini adalah total sampling. Analisis data dilakukan dengan univariat dan bivariat, pengujian statistik menggunakan uji Chi Square $\left(\mathrm{x}^{2}\right)$, dilanjutkan dengan analisis multivariat dengan uji regresi logistik untuk mengetahui pola hubungan antar variabel. Hasil Penelitian : Sebagian responden mempunyai pengetahuan cukup sebanyak 6 responden $(54,5 \%)$. Hampir seluruhnya Ibu mempunyai sikap Positif sebanyak 54,5\%. Hampir seluruhnya responden mempunyai Perilaku Kurang sebanyak 90,9\%.

Hasil uji statistik diperoleh hubungan bermakna antara antara Perilaku Ibu terhadap status gizi balita dengan nilai $\mathrm{p}$ sebesar 0,009 dimana $\mathrm{p}<\alpha$. sedangkan pengetahuan dan sikap ibu tidak berhubungan secara bermakna terhadap status gizi $(\mathrm{p}>0,05)$.

Pelaksanaan program TPG juga sangat membantu ibu dalam meningkatkan status gizi balita, dalam TPG ibu akan lebih memahami akan kebutuhan nutrisi anak, dan bagaimana cara mengolah makanan dengan baik dan benar, sehingga bisa diterapkan dalam kehidupan sehari hari,yang secara tidak langsung tindakan ibu tersebut akan melanjutkan program TPG di rumah sehingga kebutuhan nutrisi balita akan terpenuhi, yang akan berdampak terhadap peningkatan status gizi balita.

The problem of malnutrition is one of the problems that is often a controversy in the territory of Indonesia. According to the 2013 Basic Health Research (Riskesdas), the number of babies under the age of five who have problems with nutritional needs has increased from $17.9 \%$ in 2010 to $19.6 \%$. Another problem related to the nutritional needs of children under five is the existence of stunting in Indonesia. Indonesia is number five in the world due to the high prevalence rate in stunting. The purpose of this study was to analyze the Nutrition Restoration Garden program on the nutritional status of children under five in the working area of Tembelang District.

This study used an analytic observational method with a retrospective cohort study design. The population in this study were all mothers of children under five who had malnutrition in the village of Gabus Banaran \& Desa Pulo Gedang, a number of 36 respondents. The sampling technique used in this study was total sampling. Data analysis was performed using univariate and bivariate, statistical testing using the Chi Square $\left(\mathrm{x}^{2}\right)$ test, followed by multivariate analysis with logistic regression to determine 
the pattern of relationships between variables. Results: Some respondents had sufficient knowledge as many as 6 respondents $(54.5 \%)$. Almost all mothers have a positive attitude as much as $54.5 \%$. Almost all respondents have less behavior as much as $90.9 \%$.

The statistical test results obtained a significant relationship between maternal behavior and nutritional status of children under five with a p value of 0.009 where $p$ $<\alpha$. meanwhile, maternal knowledge and attitudes did not have a significant relationship with nutritional status ( $\mathrm{p}>0.05)$.

The implementation of the TPG program also greatly helps mothers in improving the nutritional status of children under five, in TPG mothers will better understand the nutritional needs of their children, and how to process food properly and correctly, so that it can be applied in daily life, which indirectly the mother's actions will continuing the TPG program at home so that the nutritional needs of toddlers will be met, which will have an impact on improving the nutritional status of toddlers.

\section{Pendahuluan}

Zat gizi adalah komponen yang sangat penting yang dibutuhkan oleh tubuh, teurtama pada usia balita karena pada usia balita pertumbuhan sel-sel otak berkembang dengan pesat. Zat gizi pada usia balita harus sangat diperhatikan karena pertumbuhan dan perkembangan saat ini menentukan keadaannya pada saat tumbuh dewasa. Karena sel otak menjadi pondasi utama kecerdasan setiap balita. Sebenarnya pertumbuhan sel otak itu sudah dimulai sejak berada di alam rahim sampai usia 2 tahun setelah lahir, dan akan semakin melambat saat usia 3-4 tahun. Maka di masamasa ini balita harus diberikan makanan yang baik dan sehat mengandung zat gizi yang baik untuk pertumbuhan otak. (Susanti, 2013).

Status gizi balita merupakan salah satu indicator yang menggambarkan tingkat status gizi masyarakat. Salah satu cara penilaian status gizi balita adalah dengan pengukuran antopometri yang menggunakan Indeks Massa Tubuh (IMT) yaitu pengukuran tubuh dibandingkan umur, antara lain Berat Badan menurut Umur (BB/U), Berat Badan menurut Tinggi Badan, atau Tinggi Badan menurut Umur (TB/U). Jumlah balita di Kabupaten Jombang pada tahun 2014 sebesar 102.578 balita sedangkan yang ditimbang 77.223 balita. Dari hasil penimbangan diketahui balita yang BGM 372 balita $(0,48 \%)$. Sedangkan jumlah balita yang gizi kurang 4.160 balita $(6,54 \%)$ dan gizi buruk $372(0,53 \%)$. Keadaan ini menunjukkan perkembangan yang bagus dimana jumlah balita BGM menurun dibandingkan dengan tahun 2013 yaitu balita BGM sebesar 462 balita $(0,57 \%)$, Balita Gizi Kurang 3791 balita (5,7\%), Balita Gizi Buruk 462 balita $(0,69 \%)$. (seksi gizi dinkes kab. Jombang 2014)
Masalah gizi buruk merupakan salah satu masalah yang sering menjadi kontroversi di wilayah Negara Indonesia ini. Menurut Riset Kesehatan Dasar (Riskesdas) 2013, jumlah bayi dibawah usia lima tahun yang mengalami masalah dengan kebutuhan gizi meningkat dari angka 17,9\% tahun 2010 menjadi 19,6\%. Masalah lain yang berkaitan dengan kebutuhan gizi pada balita adalah adanya stunting di Indonesia. Indonesia menjadi urutan nomer lima di dunia akibat angka pravalensi yang cukup tinggi pada stunting. Stunting adalah ketidaksesuaian antara tinggi badan balita dengan usia yang seharusnya atau bisa dikatakan tinggi badannya lebih rendah. Salah satu contoh lagi permasalahan gizi di Indonesia adalah Mal nutrisi yaitu gangguan kesehatan yang terjadi karena tubuh tidap dapat mengabsorpsi nutrisi dengan baik atau sebaliknya tubuh tidak mendapatkan nutrisi yang cukup. Seharusnya, tubuh dapat beraktivitas dengan baik jika mendapatkan gizi, nutrisi maupun energy yang seimbang.

Dengan adanya berbagai macam masalah gizi maka pemerintah sendiri sudah melakukan berbagai macam upaya. Salah satunya yang dilakukan pemerintah Kabupaten Jombang pada tahun 2009 untuk mengatasi permasalahan gizi tersebut adalah dengan membentuk Taman Pemulihan Gizi (TPG). Di taman pemulihan gizi para ibu yang memiliki anak usia dibawah lima tahun di berikan pelatihan dan pembinaan mengenai kebutuhan gizi, nutrisi dan energi seorang anak secara optimal. Karena akan berkaitan langsung dengan pertumbuhan dan perkembangan si anak. Di dalam taman pemulihan gizi ini juga dilengkapi dengan alat permainan edukatif yang dapat memberikan suasana yang nyaman dan aman bagi balita.

Tetapi masalah gizi ini tidak hanya berhenti sampai disini, hasil penelitian tesis Mu'alimah 
tahun 2012 mengatakan bahwa tingkat pengetahuan kader mengenai TPG masih belum mencapai titik maksimal karena kader belum mendapatkan pelatihan. Sedangkan untuk sikap kader dalam pelaksanaan TPG itu sendiri positif karena TPG dapat menjadi salah satu solusi untuk menyelesaikan masalah gizi yang ada di Kabupaten Jombang. Materi yang didapatkan oleh kader juga tidak terstruktur dengan baik. Sehingga masyarakat maupun perangkat desa hanya mendapatkan informasi secara verbal dan belum berpartisipasi secara optimal.

Dari permasalahan tersebut maka diharapkan dari penelitian yang belum pernah dilakukan ini dapat memiliki peranan besar dalam memperbaiki kualitas gizi buruk dan gizi kurang pada balita terutama di wilayah Kabupaten Jombang. Dan dapat memiliki peran secara optimal dalam memajukan program kesehatan yang dibuat oleh pemerintah.

Tujuan dalam penelitian ini adalah untuk Menganalisis program Taman Pemulihan Gizi terhadap status gizi balita di wilayah kerja Kecamatan Tembelang.

\section{Metodologi}

Penelitian ini menggunakan penelitian observasional analitik dengan rancangan penelitian kohort retrospektif. Pada desain ini mempelajari analisis taman pemulihan gizi yang telah dilakukan tahun 2017 dengan menggunakan data sekunder untuk jumlah sasaran balita. Serta data primer saat pengisian kuesioner pada ibu balita. Populasi dalam penelitian ini adalah seluruh ibu balita yang memiliki balita gizi buruk di Desa Gabus Banaran \& Desa Pulo Gedang Kecamatan Tembelang di Kabupaten Jombang. Jumlah balita yang menderita gizi buruk dan kurang yang tersebar di tersebut berjumlah 11 balita.

Teknik sampling yang digunakan dalam penelitian ini adalah total sampling, dengan kriteria inklusi : ibu Balita yang memiliki balita dengan gizi buruk dan gizi kurang tanpa komplikasi, sedangkan kriteria eksklusi : ibu Balita yang memiliki Balita dengan gizi buruk dan gizi kurang dengan komplikasi penyakit yang menyertai.

Analisa ini digunakan untuk mencari hubungan dan meneliti hubungan antara dua variabel berbentuk nominal dengan menggunakan uji chi square.

\section{Hasil dan Pembahasan}

Tabel 1 Distribusi Frekuensi Data Umum Karakteristik Balita dan Ibu Balita Berdasarkan Data Umum di Desa Gabus Banaran \& Desa Pulo Gedang Kecamatan Tembelang Tahun 2018

\begin{tabular}{|c|c|c|}
\hline \multirow{2}{*}{ Usia } & \multicolumn{2}{|c|}{ Jumlah } \\
\hline & $\mathbf{N}$ & $\%$ \\
\hline$<36$ Tahun & 10 & 90,1 \\
\hline $36-45$ Tahun & 1 & 9,09 \\
\hline Pendidikan & \multicolumn{2}{|c|}{ Jumlah } \\
\hline Rendah & 6 & 54,5 \\
\hline Menengah & 5 & 45,5 \\
\hline Tinggi & 0 & 0 \\
\hline Pekerjaan & \multicolumn{2}{|c|}{ Jumlah } \\
\hline PNS & 0 & 0 \\
\hline IRT & 11 & 100 \\
\hline Pegawai & 0 & 0 \\
\hline Paritas & \multicolumn{2}{|c|}{ Jumlah } \\
\hline Primipara & 4 & 36,4 \\
\hline Multipara & 7 & 63,6 \\
\hline Grande & 0 & 0 \\
\hline Multipara & & \\
\hline Pengetahuan & \multicolumn{2}{|c|}{ Jumlah } \\
\hline Baik & 1 & 9,1 \\
\hline Cukup & 6 & 54,5 \\
\hline Kurang & 4 & 36,4 \\
\hline Sikap & \multicolumn{2}{|c|}{ Jumlah } \\
\hline Positif & 6 & 54,5 \\
\hline Negative & 5 & 45,5 \\
\hline Perilaku & \multicolumn{2}{|c|}{ Jumlah } \\
\hline Cukup & 1 & 9,1 \\
\hline Kurang & 10 & 90,9 \\
\hline
\end{tabular}

Sumber : Data Primer Tahun 2018

Berdasarkan table 1 dapat dilihat bahwa menurut usia menunjukkan bahwa usia Ibu balita hampir seluruhnya berusia < 36 tahun sebanyak 10 orang $(90,1 \%)$, berdasarkan pendidikan Ibu menunjukkan bahwa sebagian besar Ibu balita berpendidikan rendah dengan jumlah 6 Orang $(54,5 \%)$, menurut pekerjaan Ibu menunjukkan bahwa seluruhIbu bekerja sebagai Ibu Rumah Tangga sebanyak 100\%, menurut Paritas, menunjukkan bahwa Sebagian besar Ibu dengan Paritas Multipara atau dengan jumlah anak lebih dari satu sebanyak $(63,6 \%)$.

Berdasarkan pengetahuan Ibu menunjukkan bahwa sebagian responden mempunyai pengetahuan cukup sebanyak 6 responden (54,5\%), menurut sikap ibu menunjukkan bahwa hamper seluruhnya Ibu 
mempunyai sikap Positif sebanyak 54,5\%, menurut Perilaku Ibu menunjukkan bahwa hamper seluruhnya responden mempunyai Perilaku Kurang sebanyak 90,9\%.

Tabel 2 Tabel distribusi Responden Berdasarkan Status Gizi Balita di Desa Gabus Banaran \& Desa Pulo Gedang Kecamatan Tembelang Tahun 2018

\begin{tabular}{ccccc}
\hline Status Gizi & \multicolumn{2}{c}{ Sebelum } & \multicolumn{2}{c}{ Setelah } \\
& TPG & \multicolumn{2}{c}{ TPG } \\
& N & $\%$ & N & $\%$ \\
\hline $\begin{array}{c}\text { Status Gizi } \\
\text { Baik }\end{array}$ & 0 & 0 & 8 & 72,7 \\
$\begin{array}{c}\text { Status Gizi } \\
\text { Kurang }\end{array}$ & 11 & 100 & 3 & 27,3 \\
$\begin{array}{c}\text { Status Gizi } \\
\text { Buruk } \\
\text { Total }\end{array}$ & 0 & 0 & 0 & 0 \\
\hline
\end{tabular}

Sumber : Data Primer Tahun 2018

Berdasarkan table 2 dapat dilihat bahwa menurut status gizi menunjukkan bahwa pada sebelum dilaksanakannya TPG status gizi balita seluruhnya memiliki status gizi kurang sebanyak $100 \%$ dan setelah TPG hamper seluruhnya responden mempunyai status gizi baik sebanyak 8 responden $(72,7 \%)$ dan sebagian kecil responden mempunyai status gizi balita kurang dengan jumlah 3 (27,3\%).

Tabel 3 Tabel Tabulasi Silang Pengetahuan dengan Status Gizi Setelah TPG di Desa Gabus Banaran \& Desa Pulo Gedang Kecamatan Tembelang Tahun 2018

\begin{tabular}{|c|c|c|c|c|c|}
\hline \multirow[t]{3}{*}{$\begin{array}{l}\text { Pengetah } \\
\text { uan }\end{array}$} & \multicolumn{4}{|c|}{$\begin{array}{c}\text { Status } \\
\text { Gizi }\end{array}$} & \multirow[t]{3}{*}{$\begin{array}{c}\text { Tot } \\
\text { al }\end{array}$} \\
\hline & \multicolumn{2}{|c|}{$\begin{array}{l}\text { Status gizi } \\
\text { kurang }\end{array}$} & \multicolumn{2}{|c|}{$\begin{array}{l}\text { Status gizi } \\
\text { baik }\end{array}$} & \\
\hline & $\mathrm{N}$ & $\%$ & $\mathrm{n}$ & $\%$ & \\
\hline Baik & 0 & 0 & 100 & 100 & 1 \\
\hline Cukup & 1 & 16,7 & 5 & 83,3 & 6 \\
\hline Kurang & 2 & 50 & 2 & 50 & 4 \\
\hline
\end{tabular}

Berdasarkan table 3 dapat dilihat bahwa Ibu dengan pengetahuan cukup mempunyai anak dengan $(83,3 \%)$.
Tabel 4. Tabel Tabulasi silang Sikap Ibu dengan Status Gizi Setelah TPG di Desa Gabus Banaran \& Desa Pulo Gedang Kecamatan Tembelang Tahun 2018

\begin{tabular}{|c|c|c|c|c|c|}
\hline \multirow[t]{3}{*}{ Sikap } & \multicolumn{4}{|c|}{ Status Gizi } & \multirow[t]{3}{*}{ Total } \\
\hline & \multicolumn{2}{|c|}{$\begin{array}{l}\text { Status gizi } \\
\text { kurang }\end{array}$} & \multicolumn{2}{|c|}{$\begin{array}{c}\text { Status gizi } \\
\text { baik }\end{array}$} & \\
\hline & $\mathrm{N}$ & $\%$ & $\mathrm{n}$ & $\%$ & \\
\hline Positif & 2 & 20 & 4 & 80 & 6 \\
\hline Negatif & 1 & 33,3 & 4 & 66,7 & 5 \\
\hline
\end{tabular}

Sumber : Data Primer Tahun 2018

Berdasarkan table 4 dapat dilihat bahwa Ibu dengan sikap positif mempunyai anak dengan status gizi baik dengan jumlah 4anak $(80 \%)$.

Tabel 5 Tabel Tabulasi silang Tindakan Ibu dengan Status Gizi Setelah TPG di Desa Gabus Banaran \& Desa Pulo Gedang Kecamatan Tembelang Tahun 2018

\begin{tabular}{|c|c|c|c|c|c|}
\hline \multirow[t]{3}{*}{ Tindakan } & \multicolumn{4}{|c|}{$\begin{array}{c}\text { Status } \\
\text { Gizi }\end{array}$} & \multirow[t]{3}{*}{ Total } \\
\hline & \multicolumn{2}{|c|}{$\begin{array}{c}\text { Status gizi } \\
\text { kurang }\end{array}$} & \multicolumn{2}{|c|}{$\begin{array}{c}\text { Status gizi } \\
\text { baik }\end{array}$} & \\
\hline & $\mathrm{N}$ & $\%$ & $\mathrm{n}$ & $\%$ & \\
\hline Kurang & 2 & 20 & 8 & 80 & 10 \\
\hline Cukup & 1 & 100 & 0 & 0 & 1 \\
\hline \multicolumn{5}{|c|}{ Total } & 11 \\
\hline
\end{tabular}

Sumber : Data Primer Tahun 2018

Berdasarkan table 5 dapat dilihat bahwa Ibu dengan tindakan yang kurang mempunyai anak dengan status gizi baik dengan jumlah 8 anak $(80 \%)$.

Tabel 6 Tabel Pengaruh Pengetahuan, Sikap dan Tindakan Ibu terhadap Status Gizi Balita

\begin{tabular}{lc}
\hline \multicolumn{1}{c}{ Karakteristik } & Nilai $\mathbf{~ p}$ \\
\hline Pengetahuan & 0,415 \\
Sikap & 0,621 \\
Tindakan & $\mathbf{0 , 0 0 9}$
\end{tabular}

Sumber : Hasil Olah data dengan menggunakan SPSS

Berdasarkan table 6 dapat dilihat bahwa dari karakteristik ibu yang mempunyai pengaruh terhadap status gizi balita adalah karakteristik Tindakan, dengan nilai $\mathrm{p}$ sebesar 0,009 dimana $\mathrm{p}$ $<\alpha$. Dengan demikian Tindakan Ibu mempunyai pengaruh terhadap Status Gizi balita. 
PEMBAHASAN

\section{Karakteristik Pengetahuan, Sikap dan Tindakan Ibu}

Berdasarkan hasil penelitian didapatkan hasil bahwa pada tabel 1 menunjukkan bahwa sebagian besar responden mempunyai pengetahuan cukup sebanyak 6 responden $(54,5$ $\%)$. Pengetahuan merupakan hasil tahu dan halini terjadi setelah orang melakukan penginderaan terhadap suatu objek tertentu, penginderaan dapat terjadi melalui panca indera manusia yaitu indra penglihatan, pendengaran penciuman, rasa dan raba. Sebagian besar pengetahuan manusia didapat dari mata dan telinga (Notoatmodjo, 2007). Pengetahuan merupakan domain yang sangat penting dalam membentuk sikap dan tindakan seseorang. Pengetahuan seseorang akan meningkat bila mendapat informasi yang jelas, bertanggung jawab dan terarah (Notoatmodjo, 2010). Dalam hal ini sebagian besar responden berpengetahuan cukup, yang artinya ibu balita mempunyai cukup pengetahuan tentang status gizi yang ditunjang dengan usia ibu yang relative muda dengan usia $<36$ tahun sebanyak 10 orang $90,1 \%$, dimana pada usia ini ibun mempunyai rasa keingin tahuan yang tinggi,sehingga mereka akan berusaha mendapatkan informasi tentang status gizi balita darimanapun sumbernya.

Berdasarkan table 1 dapat dilihat bahwa hampir seluruhnya Ibu mempunyai sikap Positif sebanyak 54,5\%. Pembentukan dan perubahan sikap akan ditentukan oleh dua faktor, yaitu faktor internal dan faktor eksternal dimana ibu mempunyai cara dalam menanggapi dunia luar dengan selektif sehingga tidak semua yang datang akan diterimaatau ditolak dan faktor eksternal adalah keadaan keadaan yang ada di luar individu yang merupakan stimulus untuk membentuk dan mengubah sikap, bisa diartikan ibu yang mempunyai pengetahuan cukup tidak serta merta akan digunakan pengetahuannya itu dalam tindkan, ibu akan memilih informasi yang telah didapat untuk dapat diaplikasikan terhadap balitanya.

Berdasarkan table 1 menunjukkan bahwa hampir seluruhnya responden mempunyai Perilaku Kurang sebanyak 90,9\%. Perilaku ibu terhadap balita dapat dipengaruhi oleh pengetahuan dan sikap ibu, salah satu faktor yang dapat mempengaruhi perilaku adalah pendidikan. Berdasarkan table 4.2 dapat dilihat bahwa sebagian besar Ibu balita berpendidikan rendah dengan jumlah 6 Orang $(54,5 \%)$. Tingkat pendidikan sangat berpengaruh terhadap perubahan sikap dan perilaku, dengan tingkat pendidikan yang tinggi maka akan memudahkan seseorang untukmenyerap informasi dan bisa mengimplementasikan dalam perilaku atau tindakan nyata sehari hari. Sehingga dengan pendidikan yang rendah maka perilaku ibu dalam mengimplementasikan kepada balitanya juga akan kurang.

\section{Status gizi balita sebelum dan setelah pelaksanaan TPG}

Berdasarkan table 2 dapat dilihat bahwa menurut status gizi menunjukkan bahwa pada sebelum dilaksanakannya TPG status gizi balita seluruhnya memiliki status gizi kurang sebanyak $100 \%$ dan setelah TPG hamper seluruhnya responden mempunyai status gizi baik sebanyak 8 responden $(72,7 \%)$ dan sebagian kecil responden mempunyai status gizi balita kurang dengan jumlah $3(27,3 \%)$. TPG adalah kegiatan untuk menanggulangi masalah tentang status gizi pada balita yang didalamnya terdapat pelaksanaan kegiatan bermanfaat lainnya seperti permainan edukatif, pemantauan tumbuh kembang anak serta tempat menemukan solusi yang positif untuk masalah kekurangan gizi. Dimana Tujuan TPG adalah untuk memperbaiki status gizi kurang dan buruk menjadi baik, serta memepertahankan status gizi balita yang sudah baik. Hal ini dibuktikan dnegan adanya peningkatan status gizi balita yang semula mempunyai status gizi kurang, kemudian mengalami peningkatan status gizi menjadi baik.

Pelaksanaan TPG dimulai dari mengumpulkan balita sesuai dengan sasaran kemudian dilanjutkan dengan menyusun menu makanan yang sehat dan bergizi seimbang di tempat pelaksanaan TPG. Setelah itu dilakukan pengukuran pengukuran antropometri (berat badan, tinggi badan dan lingkar kepala). Lalu dilanjutkan dengan pemeriksaan medis oleh dokter umum di hari pertama pelaksaaan TPG. Di hari berikutnya pengolahan menu makanan yang dilakukan oleh ibu balita didampingi oleh bidan, ahli gizi dan kader sesuai jadwal yang telah disepakati sebelumnya. Kemudian melakukan stimulasi tumbuh kembang terhadap anak juga diikuti dengan screening tumbuh kembang menggunakan alat permainan edukatif. Penyuluhan tentang kesehatan anak dilakukan oleh petugas kesehatan dari Puskesmas dan dari institusi pendidikan kesehatan. Kegiatan yang dilakukan pada TPG (Taman Pemulihan Gizi) sangatlah bermanfaat yang dibuktikan dengan keberhasilan program ini di Puskesmas Jatiwates 
tepatnya di Desa Gabus banaran yang mampu meningkatkan status gizi balita yang semula status gizi kurang menjadi status gizi baik.

\section{Pengaruh Pengetahuan, Sikap dan Tindakan Ibu terhadap Status Gizi Balita}

Berdasarkan table 6 dapat dilihat bahwa dari karakteristik ibu yang mempunyai pengaruh terhadap status gizi balita adalah karakteristik Tindakan, dengan nilai $\mathrm{p}$ sebesar 0,009 dimana $\mathrm{p}<\alpha$. Dengan demikian Tindakan/ perilaku Ibu mempunyai pengaruh yang signifikan terhadap Status Gizi balita. Hasil penelitian mengenai perilaku dengan status gizi dapat diketahui terdapat hubungan bermakna antara perilaku ibu dengan status gizi balita. Hal ini sesuai dengan penelitian penelitian Metz (2002), dalam penelitiannya menunjukkan adanya hubungan antara perilaku ibu dalam pemberian makan terhadap indeks masa tubuh anak. Metz pun mengatakan bahwa untuk pencegahan obesitas pada anak perlu fokus pada perilaku orang tua disamping asupan energi dan makronutrien anak. Kemudian diperkuat oleh penelitian yang dilakukan Birch dalam Donna (2002), dalam pengasuhan, perilaku ibu dalam pemberian nutrisi sangat berkaitan dengan indeks masa tubuh atau status gizi dari anak. Perilaku atau tindakan nyata dilakukan oleh ibu terhadap balita, dengan cara mengaplikasikan apa yang ibu tahu, memahami tentang status gizi balita. Pelaksanaan program TPG juga sangat membantu ibu dalam meningkatkan status gizi balita, dalam TPG ibu akan lebih memahami akan kebutuhan nutrisi anak, dan bagaimana cara mengolah makanan dengan baik dan benar, sehingga bisa diterapkan dalam kehidupan sehari hari,yang secara tidak langsung tindakan ibu tersebut akan melanjutkan program TPG di rumah sehingga kebutuhan nutrisi balita akan terpenuhi, yang akan berdampak terhadap peningkatan status gizi balita. Hal ini selaras dengan hasil penelitian dapat dinyatakan bahwa orang tua harus lebih memperhatikan asupan gizi balita karena masalah gizi dapat mempengaruhi perkembangan anak (ratnawati, mamik, Hayu L, rini, \& fitrah, septi, 2018)

\section{Simpulan}

Berdasarkan hasil dan pembahasan pada penelitian ini dapat disimpulkan sebagai berikut:
1. Sebagian responden mempunyai pengetahuan cukup sebanyak 6 responden $(54,5 \%)$.

2. Hampir seluruhnya Ibu mempunyai sikap Positif sebanyak 54,5\%.

3. Hampir seluruhnya responden mempunyai Perilaku Kurang sebanyak 90,9\%.

4. Ada pengaruh yang signifikan antara Perilaku Ibu terhadap status gizi balita dengan nilai $\mathrm{p}$ sebesar 0,009 dimana $\mathrm{p}<\alpha$.

\section{Daftar Pustaka}

De caballero, e, sinisterra o, lagrutta, f, atalah, e. 2004. Assessment of the nutritional impact of the complementary feeding program of panama in children under five years old. 54(1):66-71. (abstr.).

De-Regil, LM, Jefferds, ME, Syletsky, AC, Dowswell, T.2011. Intermittent iron supplementation for improving nutrition and development in children under 12 years of age.

Dinas Kesehatan Kab. Jombang.2007.Pedoman Pelaksanaan Stimulasi, Deteksi dan Intervensi Dini Tumbuh Kembang Anak Di Tingkat Pelayanan Kesehatan Dasar, Jombang.

Dinas Kesehatan Kab. Jombang. 2014.Profil Dinas Kesehatan kab. Jombang, Jombang. . 2014.Profil Dinas Kesehatan kab. Jombang, Jombang.

Evanjh.2011.Pengaruh Gizi Makanan terhadap Pertumbuhan

Balita.www.ilmukeperawatan.com.Diakse s pada tanggal 24 Juni 2011.

Hidayat, AA.2010.Paradigma Kuantitatif, Surabaya : Kelapa Pariwara

Inadiar, D.2010.Skripsi Perbedaan Pola Asah, Asih, Asuh pada Balita Status Gizi Kurang dan Status Gizi Normal di Wilayah Kerja Puskesmas Peneleh Surabaya, Universitas Airlangga.

Kimutai, d, maleche-obimbo, e, kamenwa, r, murila, f.2009. Hypo-phosphataemia in children under five years with kwashiorkor and marasmic kwashiorkor. 86(7):330-6. (abstr.).

Lina, N.2010.Faktor-faktor yang Mempengaruhi Pertumbuhan dan Perkembangan Anak.wordpress.com.Diakses pada tanggal 23 September 2010.

Murti, B.2010.Desain dan Ukuran Sampel untuk Penelitian Kuantitatif dan Kualitatif di Bidang Kesehatan, Yogyakarta : Gadjah Mada University Press. 
Nirmala, D.2010.Nutrition and Food Gizi untuk Keluarga, Jakarta : Media Nusantara.

Nugroho, HSW.2009.Denver Developmental Screening Test, Jakarta : EGC

Purwaningsih, E.2009.Pengaruh Suplementasi Seng dan Besi terhadap Pertumbuhan, Perkembangan Psikomorik dan Kognitif Bayi Uji Lapangan di Indramayu Jawa Barat.eprint.undip.ac.id.Diakses pada tanggal 3 September 2015.

Ratnawati, mamik, N., Hayu L, rini, M., \& fitrah, septi, midwivery. (2018). An analysis of the improvement of nutritional status among toddlers due to nutrition recovery parks. 3791, 7-10.

https://doi.org/10.31674/mjn.2018.v10i02.011

Santrock, JW.2007.Perkembangan Anak edisi kesebelas jilid 1, Jakarta : Erlangga.

Soetjiningsih.2008.Tumbuh Kembang Anak, Jakarta : EGC.

Sudayasa, P.2010.Faktor-faktor Penyebab Kekurangan Gizi pada Balita. www.puskel.com. Diakses pada tanggal 19 September 2014.

Sunarti.2010.Pengaruh Gizi terhadap Kecerdasan.http://www.infobunda.com. Diakses pada tanggal 29 Agustus 2014.

Nursalam, 2008.Konsep dan Penerapan Metodologi Penelitian Ilmu Keperawatan. Jakarta: Salemba. , 2011. Penelitian Kuantitatif, Kualitatif dan $R \& D$. Bandung: Alfabeta.

Wijaya, AM.2009.Deteksi Dini Penyimpangan Tumbuh Kembang Anak.wordpress.com. Diakses pada 18 Desember 2014 
JurnalIlmiahKebidanan (Scientific Journal of Midwifery), Vol.7., No 1 Tahun 2021 